\title{
Analysing the relationship between idiosyncratic risk and strategic capabilities using penalty-based selection and shrinkage methods
}

\author{
Helzberg School of Management, \\ Rockhurst University, \\ 1100 Rockhurst Road, \\ Kansas City, MO 64110, USA \\ Email: wenbin.sun@rockhurst.edu \\ Email: Sudhakar.raju@rockhurst.edu \\ *Corresponding author
}

Wenbin Sun and Sudhakar Raju*

\begin{abstract}
Recent research has documented the dramatic increase in idiosyncratic risk and the under-diversification of portfolios. We provide a unique marketing perspective to the financial risk management literature by suggesting that idiosyncratic volatility can be reduced by enhancing marketing, operational and R\&D capabilities. We investigate the relationship between idiosyncratic risk, firm capabilities and financial control variables using the least absolute selection and shrinkage operator (LASSO) - a penalty-based variable selection and shrinkage technique developed in the context of 'machine learning' and 'big data' that has not been much used in the empirical marketing literature. Our results differ from those reported in the literature. Using the more stringent criterion imposed by the LASSO, we find that whereas R\&D, marketing and operational capabilities have no statistically significant individual effects, the interactive effects between marketing capability and $R \& D$ intensity have a significant effect on reducing idiosyncratic risk.
\end{abstract}

Keywords: idiosyncratic risk; marketing capability; R\&D intensity; operational capability; least absolute selection and shrinkage operator; LASSO; machine learning; big data.

Reference to this paper should be made as follows: Sun, W. and Raju, S. (2019) 'Analysing the relationship between idiosyncratic risk and strategic capabilities using penalty-based selection and shrinkage methods', Int. J. Business and Data Analytics, Vol. 1, No. 1, pp.69-88.

Biographical notes: Wenbin Sun received his $\mathrm{PhD}$ in Business Administration and is an Associate Professor in Marketing at the Helzberg School of Management, Rockhurst University. His research involves corporate social responsibility, marketing strategies, marketing analytics, firm dynamic capabilities, longitudinal view of firm strategies, and their influences on firm financial performance. His research has been published in a number of journals such as Journal of Business Research, Journal of Business Ethics, European Journal of Marketing, Journal of Marketing Management, European Management Journal, Journal of Service Theory and Practice, and so on.

Sudhakar Raju is currently the Hall Chair in Finance at the Helzberg School of Management at Rockhurst University in Kansas City, Missouri, USA where he teaches courses in financial risk management and data analytics. $\mathrm{He}$ also teaches quantitative methods at the Harvard Kennedy School, Cambridge, MA. 


\section{Introduction}

In the marketing literature, the resource-based view (RBV) of the firm conceptualises firm resources as a bundle of key strategic assets that allow its managers to execute value creating strategies (Barney, 1991; Barney et al., 2011; Terziovski, 2010; Barney and Mackey, 2005). This resource bundle enables firms to strengthen market power and obtain long-term competitive advantage. The RBV has, however, been criticised for its inability in explaining how resources are actually deployed and configured to achieve competitive advantage. While the possession of valuable resources are a necessary condition to achieve market power, firms also require complementary abilities to effectively deploy resources. The capabilities perspective argues that capabilities, more than resources, are the source of competitive advantage since capabilities are interwoven into organisational processes that cannot be replicated. Danneels $(2008,2016)$ makes a distinction between first and second order competences. Danneels defines first order competences as the ability to serve particular groups of customers or produce output using a distinct technology. On the other hand, second-order competences pertain to 'the competence to build new competences' [Danneels, (2008), p.519] such as the ability to serve new markets or use new technologies.

Though the capabilities literature has contributed several insights to the marketing discipline, several significant gaps remain. The first major gap in the literature pertains to capabilities implications for financial risk management. Among first order capabilities, marketing, operations and R\&D capability have received particular attention since these are fundamental capabilities that allow firms to pursue superior financial performance (Morgan et al., 2009; Vorhies et al., 2009). Financial performance in the empirical literature is generally taken to be synonymous with metrics like profitability, return on assets, return on investment and stock market valuation. However, an extremely important aspect of financial performance is financial risk-especially idiosyncratic (unsystematic) risk. In standard financial theory, the capital asset pricing model (CAPM) explains return as a function of three components - risk free rate of return, market risk premium and the firm's systematic risk as measured by its beta. The difference between actual and predicted return from CAPM is a measure of 'unsystematic' or 'idiosyncratic risk' - that component of total risk that arises from factors specific to the individual firm.

There is an extremely well developed literature on systematic risk and its effects on stock return. Idiosyncratic risk has not received as much focus but ever since Campbell et al. (2001) documented the sustained increase in idiosyncratic risk over the last few decades, the finance profession has become more concerned with this issue. Several researchers have called for more research in this area (e.g., Kozlenkova et al., 2014; Reibstein et al., 2009; Schulze et al., 2012). The generalised increase in idiosyncratic risk over the last decade implies that perhaps the finance profession should look beyond purely finance-based solutions to managing risk such as portfolio diversification and hedging and look to non-traditional methods of reducing risk such as strategic capabilities.

A second research gap involves the interplay between capabilities themselves. Marketing, R\&D and operations capability together constitute a critical strategic basis and the interaction between these capabilities may reveal effective approaches to managing firm risk. Several recent papers examine the manner in which marketing 
capability, operational capability and R\&D interact with one another and impact revenue and profit growth. Ahmed et al. (2014) show that both marketing and operational capabilities enhance firm performance though operational capability is more significant during economic downturns. Feng et al. (2015) demonstrate that an effective marketing department enhances firm ROA and total shareholder returns. Han et al. (2017) argue that a firm's relative strategic emphasis (measured as the difference between a firm's advertising and R\&D expenditure) may be associated with idiosyncratic risk. Sun and Price (2016) find that R\&D capability reduces the firm's default risk and this risk reduction potential is stronger for high marketing capability firms. Recent work also examines the relationship between marketing capability and its impact on retail efficiency, firm financial growth, and firm value (e.g., Morgan et al., 2009; Perks et al., 2009; Nath et al., 2010; Yu et al., 2014). These studies are not always consistent in their findings regarding the nature of interactions between capabilities. However, almost all these studies conclude that marketing capability has a positive impact on financial performance.

We examine if marketing capability is important in moderating the relationship between two internal strategic drivers (operations capability and R\&D capability) and firm idiosyncratic risk. Marketing capability in this sense not only mitigates firm risk but also acts in a complementary manner enabling other capabilities to decrease firm risk. In essence, marketing capability's risk reduction potential has moved beyond its foundations in marketing and penetrated other functional departments such as operations and $R \& D$, reflecting the broadening conceptualisation of the role of marketing.

The objective of this paper is three fold. First, we analyse the link between idiosyncratic risk and three distinct first order capabilities - marketing capability, R\&D capability and operational capability. We hypothesise that these capabilities create market-based assets, drive more stable performance and ultimately reduce idiosyncratic risk. Second, we examine if marketing capability is important in moderating the relationship between operations capability and R\&D capability on the one hand and idiosyncratic risk on the other. These two objectives taken together attempt to provide a unique marketing perspective to the financial risk management literature - we suggest that idiosyncratic risk reduction could be accomplished by methods other than traditional portfolio management techniques such as diversification or hedging.

Our third objective in this paper is to make an important methodological contribution. In much of the marketing literature, the empirical technique of choice is multiple linear regression. However, variable selection and shrinkage techniques, developed in the context of 'machine learning' offer valuable estimation alternatives (see Varian, 2014 for a survey of the innovations in big data analytics and their econometric applications). An interesting alternative to linear regression is the least absolute selection and shrinkage operator (LASSO) developed by Tibshirani $(1996,2011)$. We investigate the relationship between idiosyncratic risk, firm capabilities and financial control variables using the LASSO.

This paper is organised as follows. We first review the literature on the RBV and firm idiosyncratic risk. Second, we generate a set of hypotheses connecting marketing, operations and R\&D capability and firm risk. Third, we discuss the dataset and LASSO technique. Finally, we discuss the results and suggestions for future research. 


\section{Idiosyncratic risk}

In financial theory, the CAPM explains asset returns and risk thus:

$$
\begin{aligned}
& E R_{i}=R_{F}+\beta\left[E R_{M}-R_{F}\right]+\epsilon \\
& \sigma_{i}^{2}=\beta_{i}^{2} \sigma_{M}^{2}+\sigma_{\epsilon}^{2}
\end{aligned}
$$

where $E R_{i}$ and $E R_{M}$ refer to the expected return on the individual stock and the market, $R_{F}$ refers to the risk free rate of return, $\sigma_{i}^{2}, \sigma_{M}^{2}$ refer to the variance of the stock and market.

Beta is measured by $\beta=\frac{\sigma_{i M}}{\sigma_{M}^{2}}$, where $\sigma_{i M}$ is the covariance between the stock and market and $\sigma_{€}^{2}$ the variance of the error term. In essence, the total risk of stock $i\left(\sigma_{i}^{2}\right)$ is made up of a systematic risk component $\left(\beta_{i}^{2} \sigma_{M}^{2}\right)$ and an idiosyncratic risk component $\sigma_{\epsilon}^{2}$.

Systematic risk (measured by beta) represents the relative volatility of a firm's stock returns to changes in market returns whereas idiosyncratic risk arises from firm specific actions. Thus, return that is affected by risk factors at the microeconomic level of the firm is idiosyncratic risk. Changes in the specific competitive environment in which a firm is operating, senior management changes, incidents affecting individual firms (oil spills, lawsuits, natural disasters, malfeasance, etc.) are examples of idiosyncratic risk.

Systematic and idiosyncratic risks are not equally weighted in total risk. Rather, the latter seems to have greater importance. Goyal and Santa-Clara (2003) test the relative importance of various risk factors and find that idiosyncratic risk represents roughly $80 \%$ of total risk. There is an increasing body of research in the last few years that documents the relative importance of idiosyncratic risk (Fink et al., 2010; Nam et al., 2017). The secular increase in idiosyncratic risk was first noted by Campbell et al. (2001). In a comprehensive analysis of the volatility of common stocks, Campbell et al. find that there has been a significant increase in idiosyncratic volatility over the 35 year period from 1962-1997. Moreover, correlations among individual stocks have declined over the last two decades implying that the number of stocks needed to achieve portfolio diversification has increased. "We conclude that, although the market as a whole has not become more volatile, uncertainty on the level of individual firms has increased substantially over a 35-year period" [Campbell et al., (2001), p.3]. Campbell et al. list a number of reasons underlying the increase in idiosyncratic risk. The tendency in the last few decades to break up conglomerates and replace them with companies focused on a single line of business tends to increase idiosyncratic risk by reducing the diversification benefits embedded in conglomerates. A second reason underlying higher stock volatility is that companies issue stock earlier in their life cycles when long run prospects are unclear. A third reason is attributable to option-based executive compensation which introduces perverse incentives to assume higher levels of risk. Day trading by small individual investors may have also led to increasing idiosyncratic risk.

A paradigm of modern finance is the notion that higher risk leads to higher returns. Ang et al. (2006) conclude that stocks with higher idiosyncratic volatility have surprisingly lower return signifying that idiosyncratic risk may behave differently from aggregate risk. Wei and Zhang (2006) argue that while idiosyncratic risk can be reduced by portfolio diversification such diversification may not always be possible since increasing the number of stocks to achieve diversification benefits may entail significant 
transaction costs. Bartram et al. (2016) use data from 1963 through 2015 to find that idiosyncratic risk is high when market risk is high and this positive relationship is highly stable through time. Given that idiosyncratic risk has become more significant over time and there are significant transaction costs embedded in diversification, the above highlights an important fact-relying purely on diversification might not be the only solution for controlling firm risk. Rather, seeking other firm-specific drivers such as marketing, R\&D and operational factors may provide other fundamental solutions to managing financial risks.

\section{Hypotheses}

\subsection{Marketing capability and idiosyncratic risk}

The notion that sustained competitive advantage arises from a firm's resources can be traced to Penrose (1959). In recent decades, the definition of resources has been substantially broadened as researchers found deeper and wider connections between resources and firm performance (McWilliams and Siegel, 2011; Newbert, 2007). Resources have been defined as all assets, endowments, information and knowledge that are acquired and possessed by the firm with the goal of improving efficiency and effectiveness. Comparative advantage arises if these resources are superior to other firms.

Later work highlights the fact that resource levels alone may not be enough to help a firm achieve sustained competitive advantage. The fundamental tenet of the capability perspective is that if controlling and managing valuable, rare, non-mobile and non-substitutable resources bring success, then the ability to control and manage those resources is, in itself, important. Indeed, capabilities developed in a firm's processes will be the hardest to imitate ( $\mathrm{Wu}, 2010$; Teece, 2012). Capabilities are similar to 'glue' that integrates assets and organises them in a manner that improves a firm's efficiency and effectiveness. Among capabilities, marketing capability in particular has been found to be important in driving firm performance (Morgan et al., 2009).

A firm's marketing capability impacts its valuation and its ability to acquire financial resources both indirectly and directly. Effective marketing strategies boost market share and build customer relationships which ultimately translates into enhanced financial performance and a higher stock price. The direct channel through which marketing capability impacts firm valuation is less often considered in the literature. Investors directly observe a firm's marketing actions, strategies and capabilities and, in many cases, investors seek analyst comments on marketing situations to make their judgments and valuations (Lovett and MacDonald, 2005). Thus, a firm's ability in deploying marketing resources make shareholders more optimistic about the firm, ensure greater stockholding and lower idiosyncratic risk. GE, for instance, conveys its marketing capability to investors through trade shows. The successfully transferred sense of marketing capability increases GE's credibility to shareholders and effectively serves to reduce its stock volatility. Marketing capability, compared to other firm strategic capabilities, is more difficult for rivals to imitate because it is embedded in firm processes, based on specific market knowledge and firm experience in dealing with customer needs and competitor actions As a result, marketing capability integrates a firm's overall strategies, image and reputation and represents one of the most critical drivers in gaining competitive advantage and lowering firm specific risk. 


\subsection{R\&D capability and idiosyncratic risk}

There is fairly well established research that provides evidence that a firm's R\&D capabilities improve its long-term performance and reduce volatility. The fundamental reason is that a firm committed to $R \& D$ engages in building technological ability, facilitating innovation, designing superior products and improving efficiency. Therefore, $\mathrm{R} \& \mathrm{D}$ is a value-creation driver which strongly boosts firm performance.

The essence of the protection function of $R \& D$ rests on its special nature of erecting advantages stemming from product superiority. A new product automatically gains advantage and this advantage is translated into more stable revenue thus reducing firm idiosyncratic risk. Other studies show that R\&D not only improves firm performance but also augments a firm's market valuation (Chan et al., 2001; Mizik and Jacobson, 2003). McAlister et al. (2007) find that R\&D has the ability to consistently reduce a firm's systematic risk insulating the firm against market volatility. Similarly, Luo and Bhattacharya (2009) find that superior R\&D enhances a firm's social responsibility performance which reduces idiosyncratic risk.

\subsection{Operational capability and idiosyncratic risk}

The importance of a firm's operational activities is well documented and the degree to which a firm carries out these activities efficiently is positively associated with firm performance. In resource theory, the capabilities involved in managing and acquiring raw materials, managing production and inventory, organising work and product flows are significant driving forces for acquiring comparative advantage. For example, when a firm adopts an EDI system in its supply chain, the routinising of its order processing leads to higher purchasing efficiency. Less time and human resources involved in order processing economises on monetary resources and faster processing positively impacts customer satisfaction and profitability. Operational capability directly improves firm performance and profitability thereby reducing stock price volatility and idiosyncratic risk.

It is clear from the preceding that all three capabilities (marketing, R\&D and operational capability) reduce idiosyncratic risk. We thus hypothesise that:

$\mathrm{H}_{1} \quad$ All other things equal, a firm's marketing, R\&D intensity and operational capability lower idiosyncratic risk.

\subsection{Marketing capability's interaction with $R \& D$ and operational capability}

Prior studies that have examined the interaction between marketing and R\&D have found that marketing capability significantly strengthens R\&D (Brettel et al., 2011; Danneels, 2008; Song and Thieme, 2006). Marketing capability renders critical support to R\&D by creating consumer awareness and redirecting consumer preference towards newly developed products.

In terms of competitive advantage, $R \& D$ capability is more easily codified by competitors than marketing capability because the latter is socially more complex. When $\mathrm{R} \& \mathrm{D}$ alone is improved, its benefits are limited and unsustainable because of the ease of imitation by competitors. But when combined with marketing capability in a complementary manner, $\mathrm{R} \& \mathrm{D}$ is more likely to provide comparative advantage. The 
moderating effect of marketing capability on $R \& D$ reflects the notion that $R \& D$ interacting with marketing capability achieves stability of firm performance and lower risk. Marketing capability that supports R\&D reduces idiosyncratic risk.

Operational capability is similar to R\&D capability in that it is inherently easier to benchmark and codify than marketing capability. A firm's operational activities such as engineering, work flow and purchasing are visible and easily replicated by competitors. Marketing capability is harder for competitors to imitate and codify since it is socially more complex and constructed from processes that are path dependent, Vorhies and Morgan (2005) suggest that marketing capability has at least eight aspects that horizontally span a firm's operations. Long-term relationships between a firm and its customers leads to lower cost for a firm's internal operations through more efficient control of raw materials, work-in-process and inventory. In essence, there are two primary mechanisms through which operational capability impacts idiosyncratic risk. First, operational capability directly improves firm performance and profitability thereby enhancing stock price performance and reducing stock price volatility. In addition, operational capability generates intangible assets which function as insurance-like assets' that reduce volatility.

Several recent papers study the interaction between capabilities and firm risk. The literature, in fact, strongly indicates that capabilities confer positive externalities to other firm sectors Although synergy has been emphasised in many studies, the interaction between marketing, R\&D and operational capabilities for risk management has been rarely investigated. Some recent papers attempt to address this gap by examining the linkage between capabilities and financial performance (Kamboj et al., 2015; Yu et al., 2014) but the focus of these papers is not specifically related to idiosyncratic risk. The literature on corporate social responsibility (CSR) especially tends to focus on the interacting effects of capabilities on both CSR and firm risk. In a recent study, Mishra and Modi (2016) find that the effect of CSR on idiosyncratic risk are not significant on their own; however, they only become so in the presence of marketing capability. The effect of marketing capability on financial risk, specifically firm default risk, is explored by Sun and Price (2016) who find that R\&D capability reduces a firm's default risk and this risk reduction potential is stronger for high marketing capability

The upshot of the above discussion is that there are essentially two effects. Primary effects stemming from individual capabilities reduce idiosyncratic risk (Hypothesis 1). In addition to these primary effects, there are secondary interactive effects on idiosyncratic risk that stem from the moderating influence of marketing capability on R\&D and operations capability. Our second major hypothesis can be stated thus:

$\mathrm{H}_{2} \quad$ All other things equal, a firm's marketing capability interacts with R\&D capability and operational capability to reduce idiosyncratic risk.

\section{Data description and variable construction}

The data for this paper is derived primarily from Compustat and the Centre for Research in Security Prices (CRSP). The sample was drawn from publicly traded firms in the USA for Standard Industrial Classification (SIC) codes 35 to 39 (manufacturers of commercial machinery, computer devices, electronics and equipments, transportation equipment, instruments, etc.) for the 1996-2004 period. The firms in the sample set have a mean age 
of 9 with a range from 1 to 66 years. The dataset includes firms of different sizes ranging from 50 employees to 876,000 employees and average turnover volume of 2.4 million. This sample was chosen for two reasons. R\&D is more applicable in manufacturing than non-manufacturing sectors. The second reason was to ensure some degree of comparability with previous studies in this area (e.g., Lovett and MacDonald, 2005; Narasimhan et al., 2006; McAlister et al., 2007; Krasnikov and Jayachandran, 2008). We briefly describe the manner in which some of the most significant variables were constructed.

\subsection{Marketing capability}

Marketing capability can be defined as a firm's ability to comprehend, forecast and fulfil customer needs. Marketing capability and indeed other capabilities by their very nature are not explicitly visible. The measurement of capabilities must therefore be based on proxy measures such as expenditures on market research and advertising. Prior research in this area has used various approaches and both primary and secondary data to measure capabilities.

Following Narasimhan et al. (2006) we use stochastic frontier estimation (SFE) to model marketing capability. Marketing resources include sales, general and administrative expenses (SGA) which is a proxy for investment in marketing activities. In addition, we measure marketing capability by using receivables (REC) - a proxy for resources that firms extend to build customer relationships such as extending credit or providing customers additional time for payment. In addition, we use advertising expense (ADV), which has long been treated as a critical instrument to build intangible assets such as brand equity and customer relationships. We therefore added advertising expense (Compustat, DATA 45) as an input in the SFE. Our SFE modelling of marketing capability adopts a Cobb-Douglas type formulation common in the economics production and consumer demand literature (Cobb and Douglas, 1928; Douglas, 1976; Barros and Athanassiou, 2015; Chen et al., 2015; Paul and Shankar, 2018). Thus:

$$
\begin{aligned}
& \text { Sales }_{i t}=S G A_{i t}^{\alpha_{1}} R C_{i t}^{\alpha_{2}} A D V_{i t}^{\alpha_{3}} \\
& \operatorname{Ln}\left(\text { Sales }_{i t}\right)=\alpha_{0}+\alpha_{1} \ln \left(S G A_{i t}\right)+\alpha_{2} \ln \left(R E C_{i t}\right)+\alpha_{3} \ln \left(A D V_{i t}\right)+\varepsilon_{i t}
\end{aligned}
$$

where $i$ refers to firm $i$ in year $t$. The SFE results indicate that all three inputs are significant: SGA $\left(\alpha_{1}=0.36, p<0.01\right)$, REC $\left(\alpha_{2}=0.61, p<0.01\right)$, ADV $\left(\alpha_{3}=0.05\right.$, $p<0.01)$. We computed marketing capability from the generated efficiency scores and compared its distribution between 1996 and 2004. It is interesting to note that a number of firms that began with low marketing capabilities enhanced their capabilities by the end of the study period.

\subsection{R\&D intensity and operational capability}

R\&D capability is defined as a firm's competency in product and process innovation and in applying new technologies to create effective new products and services. R\&D intensity is typically measured by a firm's expenditure in research and development standardised relative to industry expenditure. We collected data from Compustat (DATA 46): R\&D expense by firm and scaled it with firm assets to remove size effects. 
Operational capability is defined as the skills and knowledge that enable a firm to deploy internal resources to obtain the highest cost reduction. Operations capability can be measured by rating various operational efficiency dimensions such as cost and logistics. Luo and Homburg (2008) broaden the concept by defining operational capability as the firm's ability to transform inputs such as human resources or employees $(E M P)$, cost of goods sold $(C O G S)$ and selling, general and administrative (SGA) expenses into output (Sales). Following this rationale, we measure operational capability thus:

$$
\operatorname{Ln}\left(\text { Sales }_{i t}\right)=\alpha_{0}+\alpha_{1} \ln \left(E M P_{i t}\right)+\alpha_{2} \ln \left(C O G S_{i t}\right)+\alpha_{3} \ln \left(S G A_{i t}\right)+u_{i t}
$$

The SFE results indicate that all three inputs are significant: $\operatorname{EMP}\left(a_{1}=0.06, p<0.01\right)$, $\operatorname{COGS}\left(a_{2}=0.62, p<0.01\right)$, and $A D V\left(a_{3}=0.35, p<0.01\right)$.

Operational capability is computed from the generated efficiency scores. Unlike marketing capability, operational capability exhibits no significant changes over time implying that firms in this sample focus more on enhancing marketing capability than operational capability or that operational capability has less room for enhancement.

\subsection{Idiosyncratic risk}

We used daily stock return data over various annual periods to measure idiosyncratic risk using the four factor Fama-French model. The Fama-French model implies that the firm's stock return is a function of four factors market returns $(M K T)$; the differential return between small and large stocks $(S M A L L)$; differential return between stocks with high and low book-to-market $(B M)$ values; and return momentum $(M O)$. Thus

$$
\operatorname{Return}_{i t}=\beta_{0}+\beta_{i t}^{M K T} r_{i t}^{M K T}+\beta_{i t}^{S M A L L} r_{i t}^{S M A L L}+\beta_{i t}^{B M} r_{i t}^{B M}+\beta_{i t}^{M O} r_{i t}^{M O}+\varepsilon_{i t}
$$

The $R^{2}$ resulting from the above represents the degree to which the stock co-varies with the market implying that $\left[1-R_{i t}^{2}\right]$ is the proportion of stock volatility unexplained by the market and hence a measure of firm-specific or idiosyncratic risk. Luo and Bhattacharya (2009), in line with the norm in the finance literature, adopt a log-transformed measure of risk to account for boundary issues:

$$
R_{i s k_{i t}}=\ln \left[\frac{1-R_{i t}^{2}}{R_{i t}^{2}}\right]
$$

We followed Luo and Bhattacharya's definition of risk but also used the original form $\left(1-R^{2}\right)$ as an alternative definition of idiosyncratic risk.

\subsection{Control variables}

As suggested by Ferreira and Laux (2007), we adopted a series of marketing, accounting and financial factors as control variables. We measured profitability as cash flow adjusted by total assets; leverage as the ratio between long-term debt and total assets; market-to-book as market value divided by book value; dividend payment (dividend $=1$, no dividend $=0$ ); firm age as the length of time listed in Standard's and Poor. To control for industry differences, we introduced industry environmental factors. 
Environmental munificence is obtained from a series of regressions on five-year moving windows with sales regressed on time. Essentially, the coefficient on time represents the industry growth rate and the standard error proxies for volatility (environmental dynamism). In addition, we also controlled for inter-industry competition intensity by using the Herfindahl index.

\section{Estimation methodology: regression shrinkage and variable selection using the LASSO}

In much of the marketing literature, the empirical technique of choice is linear regression. However, variable selection and shrinkage techniques developed in the context of 'machine learning' offer valuable estimation alternatives (see Varian, 2014 for a survey of the innovations in big data analytics and their econometric applications). An interesting alternative to standard linear regression is the LASSO developed by Tibshirani (1996, 2011). To our knowledge this technique has not been much used in this strand of the empirical marketing literature.

A fundamental task in econometric modelling is feature selection. In the presence of a large number of predictor variables, variable reduction and feature selection assume even more importance. A rigorous method to select predictor variables conveys several benefits - it removes redundant variables, reduces overfitting and especially, in high dimensional datasets, reduces the scale of the estimation problem by enabling algorithms to work more efficiently. Standard methods for variable selection in econometrics involve statistical tests (such as Chi-square, Akaike information criterion, Bayesian information criterion, etc.) or algorithms like regression subsets or forward/backward stepwise selection, etc. However, stepwise subset selection methods often perform poorly especially when there are a large number of predictor variables and multicollinearity is present. In these situations, penalised regression methods like the LASSO are considerably better estimation alternatives. See Morozova et al. (2015) for a discussion on the relative advantages of traditional selection methods versus penalised regression methods. For an accessible discussion of the LASSO, see Ledolter (2013).

The fundamental notion underlying the LASSO is to optimise the tradeoff between bias and variance in regression estimation where bias refers to the deviation between predicted and actual values and variance to the variability in prediction. The LASSO thus optimises the trade off between accuracy and consistency. Traditional OLS estimates minimise the residual sum of squares thereby reducing bias but at the cost of higher variance. Following Hastie et al. (2009), let $Y=f(x)+\varepsilon$ where $Y$ and $X$ are response and predictor variables, $\varepsilon$ is an error term such that $E(\varepsilon)=0$, $\operatorname{Var}(\varepsilon)=\sigma^{2}$ and $\varepsilon \sim N\left(0, \sigma_{\varepsilon}\right)$. The expected prediction error of a regression fit $\hat{f}(x)$ at an input point $X=x_{0}$ can then be decomposed as:

$$
\begin{aligned}
\operatorname{Err}\left(x_{0}\right) & =E\left[\left(Y-\hat{f}\left(x_{0}\right)\right)^{2} \mid X=x_{0}\right] \\
& =\left[E\left[\hat{f}\left(x_{0}\right)\right]-f\left(x_{0}\right)\right]^{2}+E\left[\hat{f}\left(x_{0}\right)-E\left[\hat{f}\left(x_{0}\right)\right]\right]^{2}+\sigma_{\varepsilon}^{2} \\
& =\text { Bias }^{2}+\text { Variance }+ \text { Irreducible error }
\end{aligned}
$$


where the first term captures the amount by which the average estimate differs from the true mean, the second term captures the expected squared deviation of $\hat{f}\left(x_{0}\right)$ around its mean and the last term represents the noise term in the true relationship that cannot be reduced by the model. The fundamental objective of the LASSO is to solve the quadratic programming problem given by:

$$
\hat{\beta}_{\text {LASSO }}=\arg \min _{\beta}\left\{\sum_{i=1}^{N}\left[y_{i}-\sum_{j=1}^{k} x_{i j} \beta_{j}\right]^{2} \text { subject to } \sum_{j=1}^{k}\left|\beta_{j}\right|\right\} \leq t
$$

where $y_{i}$ refer to centred response variables, $x_{i j}$, to the standardised predictors, $x_{i j}, i=1,2$, $\ldots . . N ; j=1,2, \ldots k$ and $t$ is a tuning parameter. The quadratic programming problem above minimises the sum of squares with a linear inequality constraint given by $\Sigma\left|\beta_{j}\right| \leq t$. The parameter $t$ is a user defined parameter that controls the degree of shrinkage. Smaller values of $t$ result in a higher amount of shrinkage. For small enough values of $t$, some of the coefficients may be zeroed out leading to considerable model simplification. In practice, popular LASSO algorithms such as least angle regression (LARS) proposed by Efron et al. (2004) uses a shrinkage factor defined by:

$$
s=\frac{t}{\sum_{j=1}^{k}\left|\beta_{j}\right|}
$$

where $s \in(0,1)$. Note that $s=0$ implies that all coefficients are zero, $s=1$ leads to the least squares solution and values in between reflect various degrees of shrinkage. The optimal value for s is typically chosen by a technique called 'cross-validation'.

In settings where there are a large number of predictor variables, the LASSO performs consistently superior variable selection. However, the utility of penalty-based, shrinkage methods like the LASSO is not limited only to the high dimensional settings of big data. "The usefulness of shrinkage methods is widely discussed in high-dimensional settings but not limited to only this case. These methods can also be applied to a modest number of dimensions when sparsity in the estimated model is desired" [Chand, (2012), p.120].

\section{Estimation and empirical results}

In the overall model structure, the dependent variable is the firm's idiosyncratic risk (RISK). The basic model is given by:

$$
R I S K=\beta_{0}+\sum_{i=1}^{17} \beta_{i} X_{i}+\varepsilon_{t}
$$

The critical variables of interest - marketing capability, operational capability and R\&D intensity were estimated from a sample of publicly traded firms over the 1996-2004 period. Rather than focusing on multiple periods with complex interacting time varying effects, we apply the model to the latest period for which we have consistent data. The final list of independent variables (see Table 1) is based on 201 manufacturing firms for the 2004 period. 
Table 1 List of variables and sequence of LASSO moves

\begin{tabular}{lll}
\hline Predictor variables & & \\
\hline Total assets & Step 1 & Size \\
Leverage & Step 2 & Marketing capability and R\&D intensity \\
Market-to-book & Step 3 & Environmental dynamism \\
Age & Step 4 & Herfindahl index \\
R\&D intensity & Step 5 & Operational capability and R\&D intensity \\
Size & Step 6: & Operational capability \\
Environmental munificence & Step 7 & Operational capability and R\&D intensity \\
Environmental dynamism & Step 8 & R\&D intensity \\
Herfindahl index & Step 9 & Total assets \\
Marketing capability & Step 10 & Leverage \\
Operational capability & Step 11 & Marketing capability \\
Dividend & Step 12 & Cash flow ROA \\
Cash flow volatility & & \\
Cash flow ROA & & \\
Interaction 1: Marketing capability and & & \\
Operational capability & & \\
Interaction 2: Marketing capability and & & \\
R\&D intensity & & \\
Interaction 3: Operational capability & & \\
and R\&D intensity & & \\
\hline
\end{tabular}

The first column of Table 1 lists all 17 predictor variables. Generally, there are two methods to address problems that arise from such a large number of predictors. The first method is to apply multiple comparison adjustments such as the Bonferroni adjustment. Alternatively, one can apply a regularised version of the least squares adjustment that constrains the size and number of estimates. LASSO does the latter.

In this paper, we apply the LASSO algorithm - LARS (see Efron et al., 2004 for more details). The result of the LASSO algorithm is reported in the second column of Table 1. Table 1 shows the sequence in which variables enter the model as one relaxes the lasso constraint. The first variable to enter the model (step 1) is Size, followed by the interaction variable between Marketing capability and R\&D intensity, followed by Environmental dynamism, Herfindahl index (market competition), Operational capability and R\&D intensity, etc. Clearly, the interactive effects of marketing capability and R\&D intensity as well as the interactive effects of Operational capability and R\&D intensity have significant effects on idiosyncratic risk.

Table 2 reports LASSO estimates as a function of the shrinkage factor, $s$. At the extremes, $s=0$ all coefficient estimates are shrunk to zero whereas $s=1$ leads to OLS estimates. Table 2 shows LASSO estimates at various degrees of shrinkage. 
Table 2 LASSO coefficients

\begin{tabular}{lcccccc}
\hline Shrinkage factor & $s=.05$ & $s=.10$ & $s=.25$ & $s=.50$ & $s=.75$ & $\begin{array}{c}s=1(\text { OLS } \\
\text { estimates })\end{array}$ \\
\hline Total assets & 0.000 & 0.000 & 0.000 & 0.000 & 0.000 & 0.000 \\
Leverage & 0.000 & 0.000 & 1.882 & 2.923 & 3.408 & 3.579 \\
Market to book & 0.000 & 0.000 & 0.000 & 0.000 & 0.004 & 0.006 \\
Age & 0.000 & 0.000 & 0.000 & -0.301 & -0.419 & -0.439 \\
R-D intensity & 0.000 & 0.000 & -3.421 & -0.960 & -3.567 & -7.988 \\
Size & -0.508 & -0.785 & -1.257 & -1.410 & -1.452 & -1.446 \\
Environmental munificence & 0.000 & 0.000 & 0.286 & 1.488 & 1.524 & 1.197 \\
Environmental dynamism & 0.000 & -5.472 & -20.45 & -17.663 & -17.865 & -18.817 \\
Herfindahl index & 0.000 & -0.044 & -1.398 & -1.396 & -1.447 & -1.515 \\
Marketing capability & 0.000 & 0.000 & 1.038 & 4.604 & -3.086 & -13.318 \\
Operational capability & 0.000 & 0.000 & -3.837 & -9.674 & -20.553 & -30.621 \\
Interaction 1 (Marketing and & 0.000 & 0.000 & 0.000 & 0.000 & 11.460 & 24.359 \\
Operational capability) & & & & & & \\
Interaction 2 (Marketing and & -1.905 & -7.891 & -6.69 & -29.580 & -40.200 & -42.553 \\
R\&D intensity) & & & & & & \\
Interaction 3 (Operational & 0.000 & 0.000 & 0.000 & 17.890 & 30.720 & 38.214 \\
capability and R\&D & & & & & & \\
intensity) & & & & & & \\
Cash flow ROA & 0.000 & 0.000 & 1.452 & 3.006 & 3.285 & 3.080 \\
Cash flow volatility & 0.000 & 0.000 & -0.017 & -0.035 & -0.039 & -0.037 \\
Dividend & 0.000 & 0.000 & 0.082 & 0.372 & 0.475 & 0.485 \\
\hline
\end{tabular}

The optimal value of the shrinkage factor, $s$, can be determined by 'cross-validation' (CV) - a powerful technique for extending the generalisability of linear regression. The notion of cross-validation is one of the most significant ideas in machine learning and has the potential to transform the manner in which research findings are validated. The basic idea is to divide a dataset into two parts - a training set and a test set. First, an estimated equation is developed based purely on the training set data. Next, to ascertain its predictive performance the estimated equation is applied to the test set data. Since the test set was not involved in developing the estimated equation, the performance of the estimated equation on the test set data is a more accurate reflection of the predictive ability and validity of the model under different statistical environments. The model is then fitted to multiple samples using resampling. The consequent variability in model results indicates the extent to which model results are stable and generalisable. Varian $(2014$, p.7) points out that "The test-train cycle and cross-validation are very commonly used in machine learning and, in my view, should be used much more in. economics.... cross-validation also turns out to be a very useful technique.... it is also a much more realistic measure of prediction performance than measures commonly used in economics."

To select the optimal value of the shrinkage factor, we used k-fold cross-validation in which the data set is randomly partioned into k subsets (folds) of approximately equal 
size. In each iteration, one of the $\mathrm{k}$ subsets is used as the test set and the other $k-1$ subsets make up the training set. Averaging the quality of the predictions using the mean squared error (MSE) across all $\mathrm{k}$ trials results in an overall measure of predictive accuracy given by:

$$
C V_{k}=\frac{1}{k} \sum_{i=1}^{k} M S E_{i}
$$

Figure 1 shows the results of $k=10$ fold cross validation along with their standard error bounds.

Figure 1 Cross validation plot

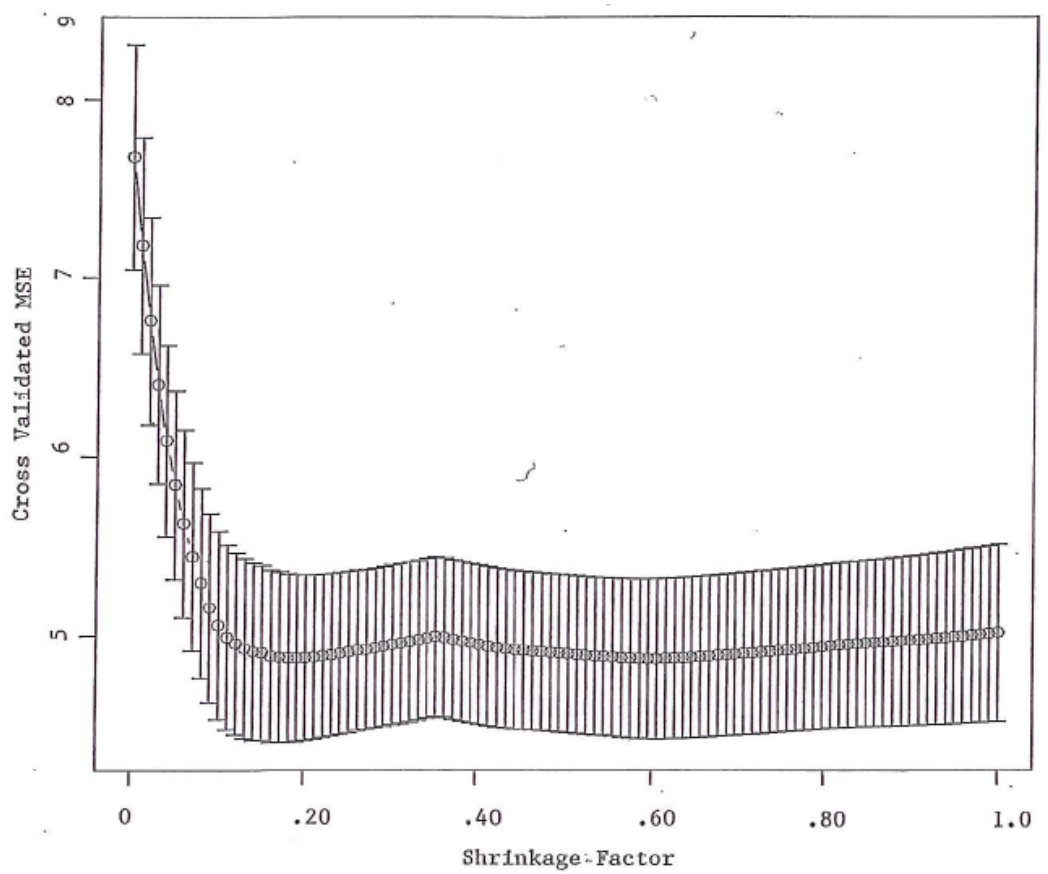

The LASSO estimates both in Table 2 and Figure 1 for $s=1$ correspond to OLS estimates. It is evident from Figure 1 that OLS estimates corresponding to $s=1$ do not result in the lowest cross validated MSE. The lowest cross validated MSE appears to correspond to a shrinkage factor of .10. We therefore focus on the LASSO estimates corresponding to this shrinkage value.

In comparing the LASSO estimates at $s=.10$ to OLS estimates, notice that 13 of the parameter values that appear in OLS are 'zeroed out' by LASSO. The remaining four variables (size, environmental dynamism, Herfindahl index and the interaction between marketing capability and R\&D intensity) are identified by LASSO as the most significant variables impacting idiosyncratic risk. Parenthetically, it is worth noting that the OLS estimates indicate that all three variables - marketing capability, operational capability and $R \& D$ intensity - have a negative impact on idiosyncratic risk - a common finding in the marketing literature. 
The first variable identified by LASSO is size. The negative coefficient on size implies that a smaller firm size increases idiosyncratic risk. The small firm effect is a well-established result in finance and the fact that smaller firms have higher idiosyncratic risk is not particularly surprising. Several recent papers have advanced fairly compelling reasons for the systemic increase in idiosyncratic risk related to firm age, and by extension, firm size. Brown and Kapadia (2007) show that an increasing trend in new listings by riskier companies constitute one possible explanation. Another compelling reason is advanced by Fink et al. (2010) who argue that the internet boom resulted in a dramatic increase in new listings and a consequent decline in the mean age at initial public offering (IPO). These effects are essentially subsumed by the size variable.

The next two variables identified by LASSO are industry environmental factors. LASSO identifies both environmental dynamism as well as the intensity of the competitive environment as measured by the Herfindahl index as significant explanatory variables for idiosyncratic risk. The negative coefficients estimated by LASSO imply that both an increase in the volatility and intensity of the competitive environment decrease idiosyncratic risk. This result can be interpreted to imply that firms that survive a competitive and volatile marketplace tend to have lower firm specific risk.

The final variable identified by LASSO as having an important effect on idiosyncratic risk is the interactive effects of marketing and $R \& D$ intensity. Higher values for this variable imply lower idiosyncratic risk. In effect, more effective marketing and higher $R \& D$ intensity lower idiosyncratic risk. While we find little support for the standalone effect of marketing, R\&D intensity and operational capability on idiosyncratic risk $\left(\mathrm{H}_{1}\right)$ we find fairly strong support for the notion that marketing capability interacts with $R \& D$ intensity to reduce idiosyncratic risk $\left(\mathrm{H}_{2}\right)$. Thus, while we find no statistically significant support for $\mathrm{H}_{1}$ we find support for $\mathrm{H}_{2}$.

\section{Discussion and implications}

In the marketing literature, the focus has typically been on the link between capabilities and firm performance where firm performance is usually defined as stock price performance. Instead of focusing on capabilities and firm performance, we focus on the link between capabilities and idiosyncratic risk - a relationship largely neglected in the marketing literature. We focus on marketing capability, $R \& D$ intensity and operational capability as well as the interaction between these capabilities and their effect on firm specific risk. We thus attempt to provide a unique marketing perspective to the financial risk management literature.

The technique used in this paper is unusual in the marketing literature. The standard techniques for variable selection in the presence of a large number of predictors is to use either regression subsets selection or principal components analysis. The LASSO technique uses a much more rigorous criterion for variable selection. Under the LASSO method of penalty-based selection and shrinkage, none of the marketing, operations or $R \& D$ variables are identified as having any statistically significant individual effects. This is in contrast to much of the marketing literature that identifies these variables as having a significant impact on firm specific risk. Under the stringent penalty-based selection criterion imposed by LASSO, only the interaction between marketing capability and R\&D intensity is identified as having a significant effect on idiosyncratic risk. 
What might explain the above results? The rejection of statistically significant individual effects of capabilities on idiosyncratic risk is easy to understand-the LASSO imposes a higher threshold for statistical significance. However, the interaction between marketing capability and R\&D intensity is significant even under this higher threshold. There are, in fact, both well-grounded theoretical reasons as well as empirical evidence regarding the positive feedback loop between marketing capability and R\&D. Sorescu et al. (2003, p.86) remark that ".... a strong set of patents alone cannot increase the sales of a radically new product if the marketing resources necessary to create awareness and increase the speed of adoption are lacking....". When R\&D alone is improved, its benefits are limited and may not be sustainable. But when combined with marketing capability in a complementary manner, R\&D is more likely to exceed what competitors can replicate. The classic example here is the iPhone whose technological superiority, aesthetic design, distribution network and marketing agreement with AT\&T is an outstanding example of the value shareholders place on the integration of R\&D with marketing. Perhaps the most comprehensive work in this strand of the literature is a meta-analysis conducted by Krasnikov and Jayachandran (2008) who find that marketing capability has a greater impact on performance than R\&D capability and operations capability.

It should be emphasised that while all these papers investigate the marketing $-R \& D$ relationship, the objective of our paper is fundamentally different in the sense that our focus is on the interactive effects of capabilities on idiosyncratic risk rather the interactive effects of capabilities on firm performance. Clearly, marketing and R\&D have complementarities as far as firm performance is concerned but their complementarity in terms of risk reduction is less clear.

McAlister et al. (2007) argues that firms with high R\&D investment adapt more efficiently to highly competitive environments reducing systematic risk. Another line of reasoning on the interactive effects of marketing and $R \& D$ on idiosyncratic risk is provided by Wilden and Gudergan (2015) who examine the role of marketing and R\&D capabilities on firm's performance. Wilden and Gudergan find that marketing capability is positively associated with firm performance in highly competitive environments whereas R\&D capability enhances performance in stable competitive environments. Thus, both marketing capability and R\&D capability interact to ensure survivability but their relative risk reduction impact differs based on the nature of the competitive environment.

The finding that the interactive effect of $R \& D$ and marketing capability outweigh individual effects of marketing, operational and $R \& D$ capabilities is an interesting finding. At low levels of marketing capability, R\&D intensity may only marginally assist a firm in reducing risk. However, when marketing capability is high, R\&D has stronger effects. In effect, the interactive impact of marketing capability with R\&D is more important than its stand-alone effect. Research that focuses on only one type of capability may be misleading since capabilities are essentially contingent one another.

\section{Limitations and future research directions}

The focus of this study is on the link between firm capabilities and idiosyncratic risk. Total financial risk is however composed of both systematic risk and unsystematic or idiosyncratic risk. This study thus does not address the effect of capabilities on systematic risk. Future research could explore this more rigorously. 
The concept of marketing capability employed in this study is a general one and it has been suggested that such a capability should be examined as a series of specialised marketing capabilities (Vorhies and Morgan, 2005). Specialised marketing capabilities such as marketing communication, pricing and channel management may have their own distinct characteristics. The overall effectiveness of the general concept of marketing capability does not unconditionally indicate the effectiveness of specialised marketing capabilities in risk reduction. Vorhies et al. (2009) propose a distinction between specialised and architectural capabilities. A deeper understanding of the detailed pattern of specialised capabilities, architectural capabilities and firm risks will enhance this literature.

The secondary data approach from Compustat and CRSP has been widely adopted in studying firm attributes and has some salient advantages-objectivity, large sample size and higher generalisability. However, using primary data such as perceptual data may provide further detail by including factors that are not in the current secondary database.

The penalty-based selection and shrinkage method used in this paper has not been widely used in the empirical marketing literature. Methods like LASSO and related techniques like ridge regression can play a very useful role in model selection, validation and prediction. Research along these lines can substantially enhance the generalisability and reliability of marketing research.

\section{References}

Ahmed, M.U., Kristal, M.M. and Pagell, M. (2014) 'Impact of operational and marketing capabilities on firm performance: evidence from economic growth and downturns', International Journal of Production Economics, Vol. 154, pp.59-71.

Ang, A., Hodrick, R.J., Xing, Y. and Zhang, X. (2006) 'The cross-section of volatility and expected returns', Journal of Finance, Vol. 61, No. 1, pp.259-299.

Barney, J. (1991) 'Firm resources and sustained competitive advantage', Journal of Management, Vol. 17, No. 1, pp.99-122.

Barney, J. and Mackey, T.B. (2005) 'Testing resource-based theory', in Ketchen, D.J. and Bergh, D.D. (Eds.): Research Methodology in Strategy and Management, Vol. 2, pp.1-13, Elsevier, Greenwich, CT.

Barney, J.B., Ketchen Jr, D.J. and Wright, M. (2011) 'The future of resource-based theory: revitalization or decline?', Journal of Management, Vol. 37, No. 5, pp.1299-1315.

Barros, C.P. and Athanassiou, M. (2015) 'Efficiency in European seaports with DEA: evidence from Greece and Portugal', in Port Management, pp.293-313, Palgrave Macmillan, London.

Bartram, S.M., Brown, G. and Stulz, R.M. (2016) Why Does Idiosyncratic Risk Increase with Market Risk?, No. w22492, National Bureau of Economic Research.

Brettel, M., Heinemann, F., Engelen, A. and Neubauer, S. (2011) 'Cross-functional integration of $\mathrm{R} \& \mathrm{D}$, marketing, and manufacturing in radical and incremental product innovations and its effects on project effectiveness and efficiency', Journal of Product Innovation Management, Vol. 28, No. 2, pp.251-269.

Brown, G. and Kapadia, N. (2007) 'Firm-specific risk and equity market development', Journal of Financial Economics, Vol. 84, No. 2, pp.358-388.

Campbell, J., Lettau, M., Malkiel, B.G. and Xu, Y. (2001) 'Have individual stocks become more volatile? an empirical exploration of idiosyncratic risk', Journal of Finance, Vol. 56, No. 1, pp.1-43.

Chan, L.K., Lakonishok, J. and Sougiannis, T. (2001) 'The stock market valuation of research and development expenditures', Journal of Finance, Vol. 56, No. 6, pp.2431-2456. 
Chand, S. (2012) 'On tuning parameter selection of LASSO-type methods - a Monte Carlo study', Proceedings of the 2012, 9th International Bhurban Conference on Applied Sciences and Technology, IEEE, pp.120-129.

Chen, C-M., Delmas, M.A. and Lieberman, M.B. (2015) 'Production frontier methodologies and efficiency as a performance measure in strategic management research', Strategic Management Journal, Vol. 36, No. 1, pp.19-36.

Cobb, C.W. and Douglas, P.H. (1928) 'A theory of production', American Economic Review, Vol. 18, No. Supplement, pp.139-165.

Danneels, E. (2008) 'Organizational antecedents of second-order competences', Strat. Mgmt. J., Vol. 29, No. 5, pp.519-543.

Danneels, E. (2016) 'Survey measures of first- and second-order competences', Strat. Mgmt. J., Vol. 37, No. 10, pp.2174-2188.

Douglas, P.H. (1976). 'The Cobb-Douglas production function once again: its history, its testing, and some new empirical values', Journal of Political Economy, Vol. 85, No. 5, pp.903-916.

Efron, B., Hastie, T., Johnstone, I. and Tibshirani, R. (2004) 'Least angle regression', The Annals of Statistics, Vol. 32, No. 2, pp.407-499.

Feng, H., Morgan, N.A. and Rego, L.L. (2015) 'Marketing department power and firm performance', Journal of Marketing, September 2015, Vol. 79, No. 5, pp.1-20.

Ferreira, M.A. and Laux, P.A. (2007) 'Corporate governance, idiosyncratic risk, and information flow', Journal of Finance, Vol. 62, No. 2, pp.951-989.

Fink, J., Fink, K.E., Grullon, G. and Weston, J.P. (2010) 'What drove the increase in idiosyncratic risk during the internet boom?', Journal of Financial and Quantitative Analysis, Vol. 45, No. 5, pp.1253-1278.

Goyal, A. and Santa-Clara, P. (2003) 'Idiosyncratic risk matters!', Journal of Finance, Vol. 58, No. 3, pp.975-1007.

Han, K., Mittal, V. and Zhang, Y. (2017) 'Relative strategic emphasis and firm idiosyncratic risk: the moderating role of relative performance and demand instability', Journal of Marketing, Vol. 81, No. 4, pp.25-44.

Hastie, T., Tibshirani, R. and Friedman, J. (2009) 'The elements of statistical learning: datamining, inference, and prediction', Springer Series in Statistics, 2nd ed., Springer, New York, NY

Jacobs, B.W., Kraude, R. and Narayanan, S. (2016) 'Operational productivity, corporate social performance, financial performance, and risk in manufacturing firms', Prod. Oper. Management, Vol. 25, No. 12, pp.2065-2085.

Kamboj, S., Goyal, P. and Rahman, Z. (2015) 'A resource-based view on marketing capability, operations capability and financial performance: an empirical examination of mediating role', Procedia-Social and Behavioral Sciences, Vol. 189, pp.406-415.

Kozlenkova, I., Samaha, S. and Palmatier, R. (2014) 'Resource-based theory in marketing', Journal of the Academy of Marketing Science, Vol. 42, No. 1, pp.1-21.

Krasnikov, A. and Jayachandran, S. (2008) 'The relative impact of marketing, R\&D, and operations capabilities on firm performance', Journal of Marketing, Vol. 72, No. 4, pp.1-11.

Ledolter, J. (2013) Data Mining and Business Analytics with R, John Wiley \& Sons Inc., Hoboken, New Jersey.

Lovett, M.J. and MacDonald, J.B. (2005) 'How does financial performance affect marketing? Studying the marketing-finance relationship from a dynamic perspective', Journal of the Academy of Marketing Science, Vol. 33, No. 4, pp.476-485.

Luo, X. and Bhattacharya, C.B. (2009) 'The debate over doing good: corporate social performance, strategic marketing levers, and firm-idiosyncratic risk', Journal of Marketing, November 2009, Vol. 73, No. 6, pp.198-213.

Luo, X. and Homburg, C. (2008) 'Satisfaction, complaint, and the stock value gap', Journal of Marketing, Vol. 72, No. 4, pp.29-43. 
McAlister, L., Srinivasan, R. and Kim, M. (2007) 'Advertising, research and development and systematic risk of the firm', Journal of Marketing, Vol. 71, No. 1, pp.35-48.

McWilliams, A. and Siegel, D. (2011) 'Corporate social responsibility and financial performance: correlation or misspecification?', Strategic Management Journal, Vol. 21, No. 5, pp.603-09.

Mishra, S. and Modi, S.B. (2016) 'Corporate social responsibility and shareholder wealth: the role of marketing capability', Journal of Marketing, Vol. 80, No. 1, pp.26-46.

Mizik, N. and Jacobson, R. (2003) 'Trading off between value creation and value appropriation: the financial implications of shifts in strategic emphasis', Journal of Marketing, Vol. 67, No. 1, pp.63-76.

Morgan, N.A., Vorhies, D.W. and Mason, C.H. (2009) 'Market orientation, marketing capabilities, and firm performance', Strategic Management Journal, Vol. 30, No. 8, pp.909-920.

Morozova, O., Levina, O., Uusküla, A. and Heimer, R. (2015) 'Comparison of subset selection methods in linear regression in the context of health-related quality of life and substance abuse in Russia', BMC Medical Research Methodology, Vol. 15, No. 1, p.71.

Nam, K., Khaksari, S. and Kang, M. (2017) 'Trend in aggregate idiosyncratic volatility', Review of Financial Economics, Vol. 35, pp.11-18.

Narasimhan, O., Rajiv, S. and Dutta, S. (2006) 'Absorptive capacity in high-technology markets: the competitive advantage of the Haves', Marketing Science, Vol. 25, No. 5, pp.510-524.

Nath, P., Nachiappan, S. and Ramanathan, R. (2010) 'The impact of marketing capability, operations capability and diversification strategy on performance: a resource-based view', Industrial Marketing Management, Vol. 39, No. 2, pp.317-329.

Newbert, S.L. (2007) 'Empirical research on the resource-based view of the firm: an assessment and suggestions for future research', Strategic Management Journal, Vol. 28, No. 2, pp.121-146.

Paul, S. and Shankar, S. (2018) 'On estimating efficiency effects in a stochastic frontier model', European Journal of Operational Research, Vol. 271, No. 2, pp.769-774.

Penrose, E.T. (1959) The Theory of the Growth of the Firm, Wiley, New York.

Perks, H., Kahn, K. and Zhang, C. (2009) 'An empirical evaluation of R\&D - marketing NPD integration in Chinese firms: the Guanxi effect', Journal of Product Innovation Management, Vol. 26, No. 6, pp.640-651.

Reibstein, D., Day, G. and Wind, J. (Yoram) (2009) 'Is marketing academia losing its way?', Journal of Marketing, July, 'Guest Editorial: Is marketing academia losing its way', Vol. 37, No. 4, pp.1-3.

Schulze, C., Skiera, B. and Wiesel, T. (2012) 'Linking customer and financial metrics to shareholder value: the leverage effect in customer-based valuation', Journal of Marketing, Vol. 76, No. 2, pp.17-32.

Song, M. and Thieme, R.J. (2006) 'A cross-national investigation of the R\&D - marketing interface in the product innovation process', Industrial Marketing Management, Vol. 35, No. 3, pp.308-322.

Sorescu, A., Chandy, R. and Prabhu, J. (2003) 'Sources and financial consequences of radical innovation: insights from pharmaceuticals', Journal of Marketing, Vol. 67, No. 4, pp.82-102.

Sun, W. and Price, J.M. (2016) 'Implications of marketing capability and research and development intensity on firm default risk', Journal of Marketing Management, Vol. 32, Nos. 1-2, pp.179-206.

Teece, D.J. (2012) 'Dynamic capabilities: routines versus entrepreneurial action', Journal of Management Studies, Vol. 49, No. 8, pp.1395-1401.

Terziovski, M. (2010) 'Innovation practice and its performance implications in small and medium enterprises (SMEs) in the manufacturing sector: a resource-based view', Strategic Management Journal, Vol. 31, No. 8, pp.892-902.

Tibshirani, R. (1996) 'Regression shrinkage and selection via the lasso', Journal of the Royal Statistical Society, Series B, Vol. 58, No. 1, pp.267-288. 
Tibshirani, R. (2011) 'Regression shrinkage and selection via the lasso - a retrospective', Journal of the Royal Statistical Society, Vol. 73, No. 3, pp.273-282.

Varian, H. (2014) 'Big data: new tricks for econometrics', Journal of Economic Perspectives, Vol. 28, No. 2, pp.3-28.

Vorhies, D.W. and Morgan, N.A. (2005) 'Benchmarking marketing capabilities for sustained competitive advantage', Journal of Marketing, Vol. 69, No. 1, pp.80-94.

Vorhies, D.W., Morgan, R.E. and Autry, C.W. (2009) 'Product-market strategy and the marketing capabilities of the firm: impact on market effectiveness and cash flow performance', Strategic Management Journal, Vol. 30, No. 12, pp.1310-1334.

Wei, S. and Zhang, C. (2006) 'Why did individual stocks become more volatile?', Journal of Business, Vol. 79, No. 1, pp.259-291.

Wilden, R. and Gudergan, S. (2015) 'The impact of dynamic capabilities on operational marketing and technological capabilities: investigating the role of environmental turbulence', Journal of the Academy of Marketing Science, Vol. 43, No. 2, pp.181-199.

Wu, L-Y. (2010) 'Applicability of the resource-based and dynamic-capability views under environmental volatility', Journal of Business Research, Vol. 63, No. 1, pp.27-31.

Yu, W., Ramanathan, R. and Nath, P. (2014) 'The impacts of marketing and operations capabilities on financial performance in the U.K. retail sector: a resource-based perspective', Industrial Marketing Management, Vol. 43, No. 1, pp.25-31. 